\title{
When friction is no longer enough
}

\author{
J.H. Graaf Golder Associates Pty Ltd, Australia
}

S. Van Der Merwe Xstrata Nickel Australasia, Australia

\begin{abstract}
Managing the transition from low stress to high stress underground environments is becoming an important issue for underground mining in Western Australia, particularly as ore bodies are being proven up at deeper levels. Cosmos Nickel Operation (CNO) is a deep nickel sulphide orebody located near Leinster, Western Australia.

The friction bolt (or split set) is the rockbolt of choice for many underground operations in Western Australia. CNO used the split set with mesh or shotcrete as its only form of ground support for many years. However, with development occurring at greater depth, the ground started to behave in a different manner to before and the split set could no longer sustain the deformation associated with this transition. The serpentine altered, ultramafic host rocks began showing classic signs of squeezing rock conditions, with delamination in the walls and drive closure a common problem. The ultramafic also started to unravel and self-mine immediately after development. The footwall felsic volcanics lie at the other end of the spectrum, where the high strength and brittle nature of these rock types showed a propensity to generate strain bursting and seismic activity.

This paper discusses the trial and implementation of several new types of ground support at CNO to manage the deformation associated with a higher stress environment and challenging ground conditions. The ground support systems addressed in this paper include de-bonded cable bolts, D-bolts, Omega and resin encapsulated cable bolts.

As part of the trial and implementation process, we recognised the need to have a systematic approach to ground support selection and trial. This paper provides a basic methodology and framework for site based engineers to undertake ground support trials in a safe and efficient manner and also to aid with compliance to the change management process.
\end{abstract}

\section{$1 \quad$ Introduction}

Mining of the shallow Cosmos massive nickel sulphide deposit commenced as an open pit by Sir Samuel Mines NL in October 1999. Underground development along the llias decline commenced in mid-2002 to access the Cosmos Deeps orebody. A second underground mine accessed by the Helene Decline; Prospero, commenced development in 2006 to target the Prospero and Tapinos orebodies and was completed in 2011 due to depletion of the ore reserves. The deepest underground workings at Cosmos Deeps are approximately $900 \mathrm{~m}$ and the new orebodies lie between 900 and 1,100 m below surface (Figure 1).

The initial ground control regime at Cosmos comprised the use of weld wire mesh and split sets. Fibrecrete was used in areas that required additional surface support or in high traffic areas such as pump stations, workshops and crib rooms, with grouted cable bolts a requirement in all intersections and wide spans.

The wide spread use of fibrecrete and resin encapsulated bolts (Posimix - supplier DYWIDAG-Systems International (DSI) Mining) became a reality in Cosmos in 2007. This change in ground control regime came about for several reasons, but was predominantly driven by poor ground conditions associated with blocky and sheared footwall ultramafic lithologies in the AM2 orebody.

Historically, the massive sulphide deposits of Cosmos Deeps and AM1 were hosted in meta-sedimentary or felsic volcanic lithologies, and the occurrence of ultramafic in underground development was rare. During 
the development of the AM2 orebody, external geotechnical reviews highlighted inconsistencies in meshing standards. These reviews also suggested that mesh was not providing adequate confinement to the exposed ultramafic surfaces as there was a tendency for overbreak and unravelling to occur during and after completion of the development in ultramafic. An additional causal factor was the tendency for operators to excessively scale the weak rock mass prior to installation of the weld mesh and friction bolts. The areas that had undergone excessive unravelling typically required more intensive levels of remedial ground support including fibrecrete and cable bolts.

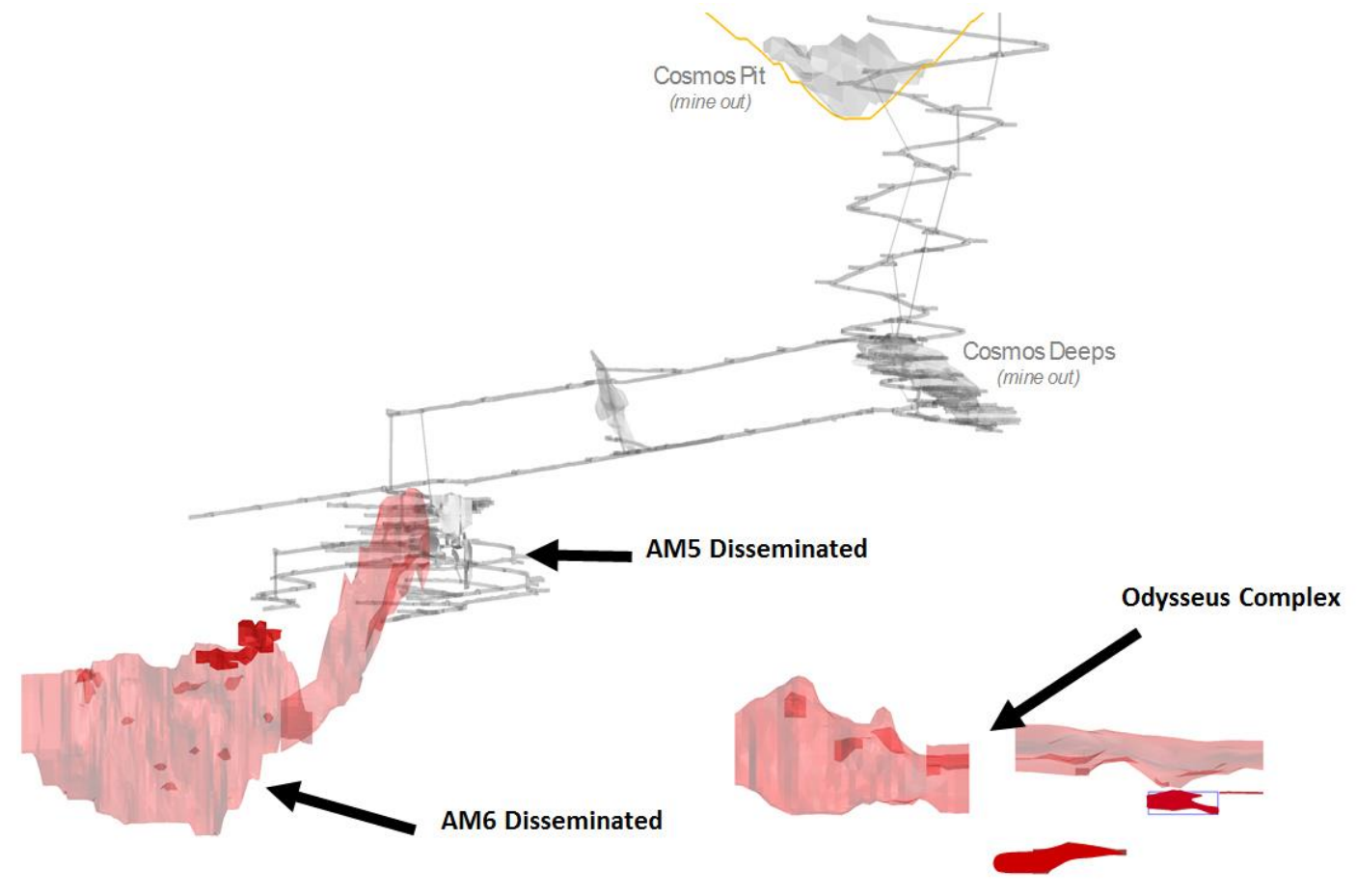

Figure 1 Section of the Cosmos Deeps Mine showing existing mine development

Due to the changes in surface support, a review of the entire ground support regime was undertaken. These reviews indicated that the split set did not have sufficient factor of safety at installed capacity to account for the increased depth of failure and rock mass densities associated with ore in the ultramafic.

Changing the ground support regimes at this stage was essential given that the rate and extent of rock mass deformation was increasing, and would likely necessitate the use of fibrecrete and resin encapsulated bolts.

In changing the ground support regime used, it was important to understand the problem, but also to realise the need for what was required.

Some basic questions for the Geotechnical Engineers to ask themselves when considering changing the ground control regime include but are not limited to:

1. What is happening to the mining induced stress environment and rock mass response to make you think you need to change the ground support regime?

2. How quickly are the conditions changing?

3. How effective are the current ground control systems?

4. Are there effective quality assurance/quality control (QAQC) processes being undertaken for you to evaluate the efficiency of the ground control regime, i.e. grout tests, bolt hole sizes, installation review, ground support audits, pull tests, and observations?

5. What was the original premise behind installing the current ground control regime? 
6. Who is installing the ground support? What is the skill set of the operator? Have they been adequately trained? What does their training comprise? What is their experience?

7. Why does the ground control need to change? Have there been any incidents? Instabilities or rock falls? Seismicity? Is the change coming as a result of corporate directive or has there been a change in risk perception?

\section{De-bonded cable bolts}

The use of de-bonded cable bolts came about during the development of the AM5 Decline. Conditions in the ultramafic decline were deteriorating considerably. These changes were attributed to:

- Increasing ground stress due to increase in depth at Cosmos Deeps Mine.

- Mining induced stresses approaching the strength of the rock mass resulting in failure.

- Stress re-distribution around freshly fired faces causing minor failure in the freshly exposed rock.

- The presence of stress anomalies (i.e. faults as well as competency contrasts between varying rock types) in particular the presence of talc in-filled shears oriented in the direction of Sigma 2 (NNE-SSW).

- Depth of failure in the ultramafic up to $1.5 \mathrm{~m}$ into the walls and back of the development excavations.

Due to the above factors, the decision was made to increase the depth of embedment of ground support in the ultramafic. In addition to this, it was becoming commonplace to see:

- Extensive cracking in fibrecrete along the backs and down sidewalls.

- Bolt plates being pulled through and on the ground in drives.

- Split sets failing through shearing and 'guillotining' of the bolt (Figure 2(a)).

- Posimix (resin encapsulated) bolts indicating signs of loading with plates deforming and even bolts failing completely (Figure 2(b)).

- Ground movement in areas where the ultramafic rock mass had been developed through at an oblique angle and movement appeared to be of a shearing nature along joints striking parallel to sub-parallel relative to the ultramafic strike direction (Figure 2(c)).

All of these factors indicated that the peak strain of the ground support elements was occurring and yielding support was required. 


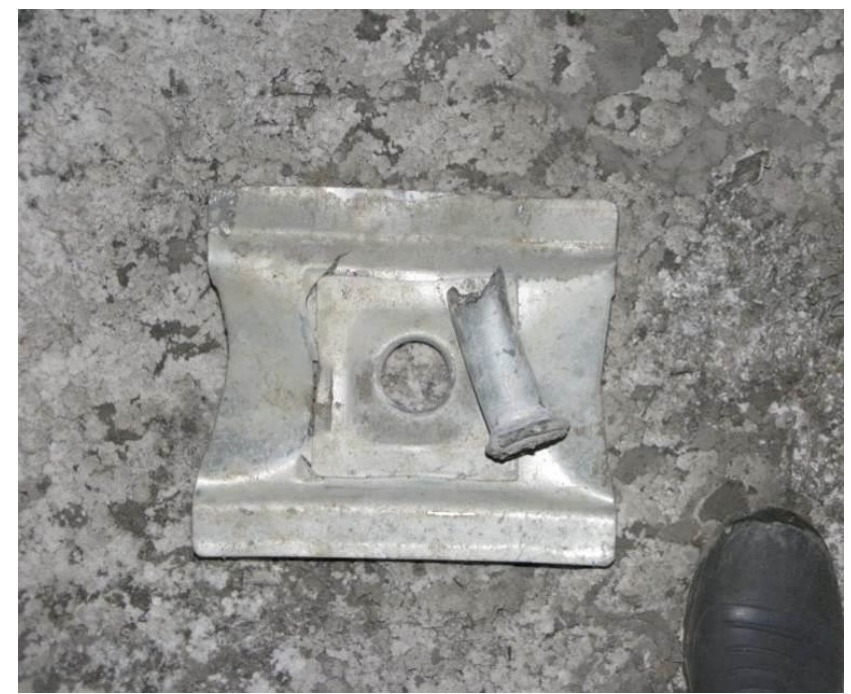

a)

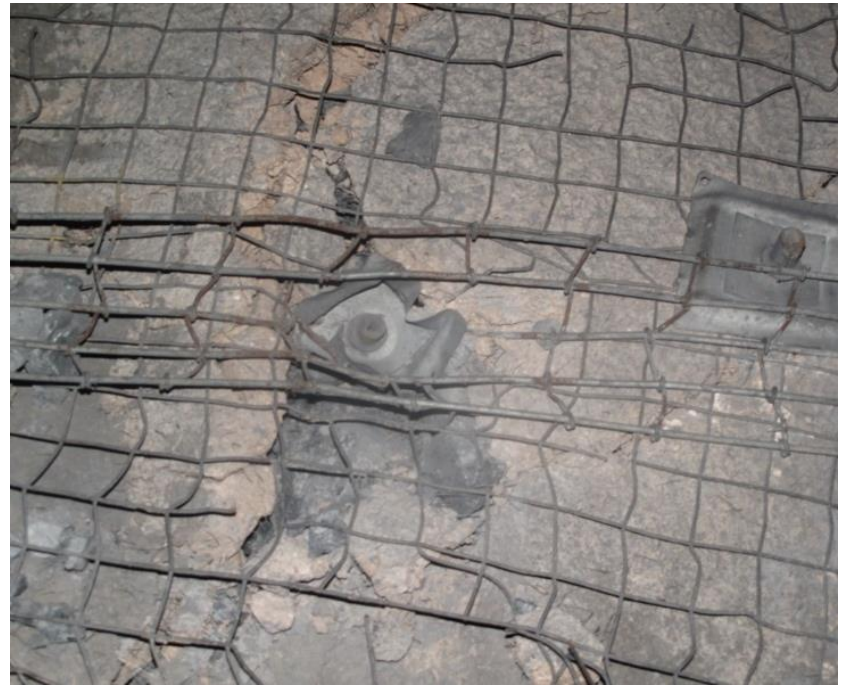

b)

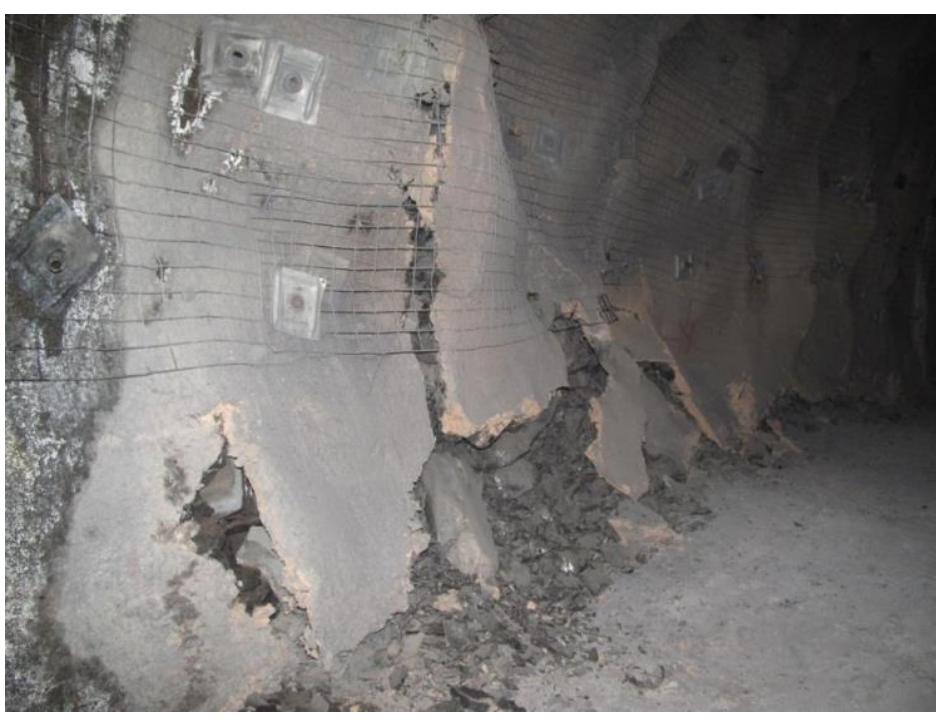

c)

Figure 2 Image a) shows a 'guillotined' split set failed through shearing of the bolt. Image b) shows cracked fibrecrete and failed resin bolts. Image c) shows typical deformation and sidewall buckling in the ultramafic

Due to the potential for the depth of failure to be $1.5 \mathrm{~m}$, the length of bolt needed to be at least $3 \mathrm{~m}$ long to provide sufficient embedment. However, the existing ground support in the decline profile comprised both $2.4 \mathrm{~m}$ and $3.0 \mathrm{~m}$ length bolts and they were already exhibiting failure. Cable bolts provided the only bolt capable of providing increased embedment depths. As the current ground support system was considered relatively stiff, the cable bolts needed to be yielding with a higher strain capacity.

Several issues were introduced as a result of this requirement:

1. Specific bolts were not immediately available. The bolt specifications had to be provided to the bolt-supplier (DSI Mining) so they could be specifically manufactured. In the meantime, the bolts were made on site as per Figure 3, using $25 \mathrm{~mm}$ grout tube cut to size and placed over a plain strand cable bolt.

2. Significant increase in ground support installation cost. The cable bolt regime was to comprise incycle, $6 \mathrm{~m}$ long, de-bonded cables, with five per ring and on a $2.5 \mathrm{~m}$ inter-ring spacing. By being installed in-cycle this resulted in additional delays in development advance rates, in addition to 
the increased ground support costs per metre. These delays in advance rate were not already factored into the short, medium and long term schedule so changes were required to scheduling and revision of the monthly and yearly development targets.

1) Install

$25 \mathrm{~mm}$

2) Grout, plate and tension as per normal procedure

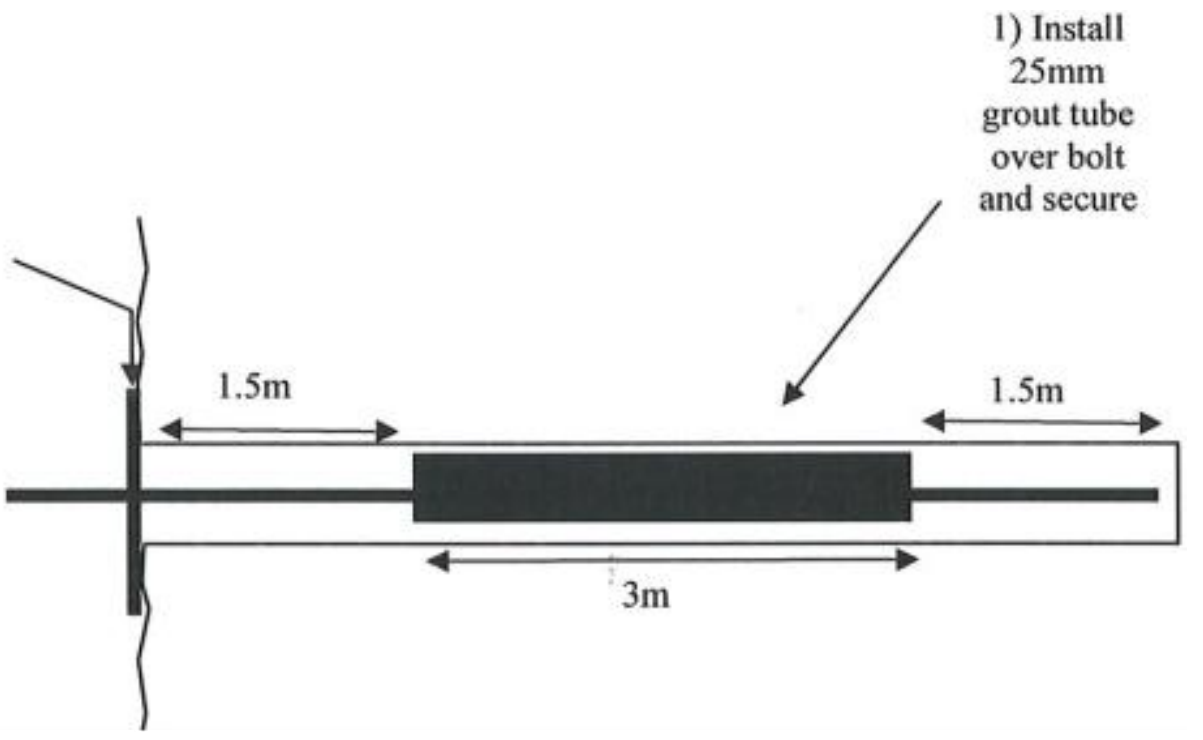

\section{Figure 3 Schematic of de-bonded cable bolt}

The implementation process was relatively straight forward, as cable bolts at CNO were already used in intersections and widespans and were installed manually as opposed to through mechanised installation. It would have been difficult to implement the de-bonded cables if a machine was used because this would have required additional training of personnel and the sourcing of the correct equipment.

Some of the learnings associated with the process involved:

- Ensuring QAQC of the bolt installation including observations of installation process, auditing, and grout testing.

- Plating and tensioning of bolts needed to be factored in before the next development cut was to advance. Limited development headings at times, or multiple headings in ultramafic could create delays in the production schedule and therefore daily and weekly planning needed to be mindful of requirements for cable bolting. Communication between key personnel was critical and necessitated a reliable geological model in order to plan the development activities.

- Installing the cable bolts too low down the walls resulted in easy targets for underground machinery. The lowest cable bolts should be installed was $2.2 \mathrm{~m}$ from the floor otherwise the tails would shred equipment tyres and break windows.

\section{D-bolts}

The high costs and slow development rates in the ultramafic resulting from the de-bonded bolts meant that new rockbolt types were regularly investigated to see if they could replace the in-cycle cables, or at least reduce the frequency of installation. The D-bolts a grouted or resin encapsulated deformable bolt (Supplier: Dynamic Rock Support) were investigated as one such option because:

- These bolts were developed to counteract both rockburst prone and squeezing rock conditions.

- The bolts are considered yielding support as anchors are firmly fixed within grout or resin whilst smooth sections between anchors are able to freely deform in response to rock dilation (Figure 3(a)). 
- Anchors are designed to act independently so that the failure of one section does not affect the others.

- They are designed to use the full strength and deformation capacity of the bolt along the entire length.

- The bolt has been tested and showed high load bearing (greater than $17 \mathrm{t}$ ) and deformation capacities.

- Static pull and drop tests showed bolt length elongates up to $14-20 \%$.

- Cumulative dynamic energy absorption is $47 \mathrm{~kJ} / \mathrm{m}$.

- The trial of these bolts involved purchasing 500 of the $2.4 \mathrm{~m}$ bolts and 500 of the $3.0 \mathrm{~m}$ bolts (Figure 4(a)). The intention was to replace the posimix bolts in the ground support regime, and also provide better support for the ultramafic.

In order to run systematic trials, two ore drives were selected in the development schedule that were not high traffic areas, or going to be used in the immediate future. This way, time dependent deformation could be monitored and adequate time for rehabilitation was allowed for in the event that these bolts did not work.

It was important to install these bolts in conditions (i.e. same rock type, stress conditions) that they would encounter over their lifecycle, rather than choosing an old part of the mine. This would not have provided an accurate representation of the behaviour. Likewise, choosing a single site would not necessarily be representative of bolt performance on a mine-wide scale.

Positive aspects of this bolt trial included:

- Easier and faster to install than the posimix bolts due to the smooth and tapered end shape of the bolt (i.e. it didn't get caught on mesh while trying to get into the bolt hole).

- Pull tested to $15 \mathrm{t}$ within 12 hours of installation.

- Smaller tails exposed on the rock surface would minimise damage to equipment (Figure 4b).

- $30 \%$ cheaper than posimix bolts.

- Potential to remove expensive and time consuming in cycle de-bonded cable bolts due to dynamic and elongation capacity.

Some of the negatives included:

- Small thread on bolt made it difficult to tighten and was damaged easily which made it difficult to screw nuts on and therefore plates could not be installed flush with the face. This also prohibited the pull testing nut from being able to screw onto the bolts, resulting in a limited number of bolts that could be tested and poor QAQC control (Figure 4(c) and 4(d)).

- At the time they were black bolts only (non-galvanised).

- The current posimix hole diameter was too big for the D-bolts and the resin cartridges slightly too small, so that there was not enough encapsulation by resin (Figure 4(c)).

- The first anchor on the bolt was set at $0.5 \mathrm{~m}$, and therefore was anchored in fractured ground around the opening. This then questions the effectiveness of the elongation and capacity if it is based on elongating the three anchors. 


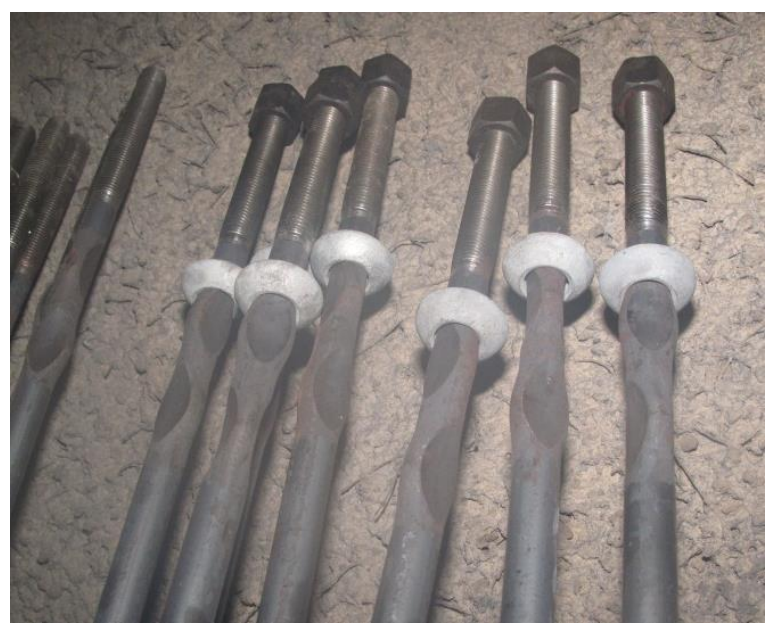

a)

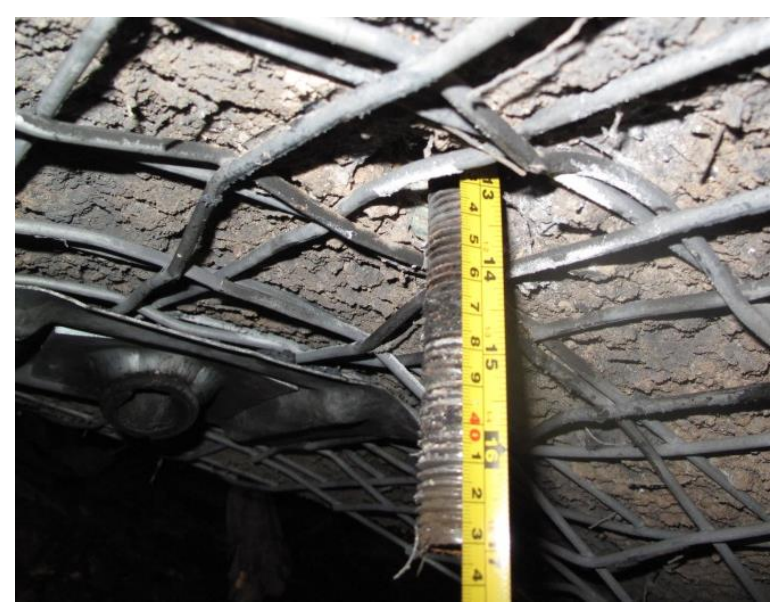

c)

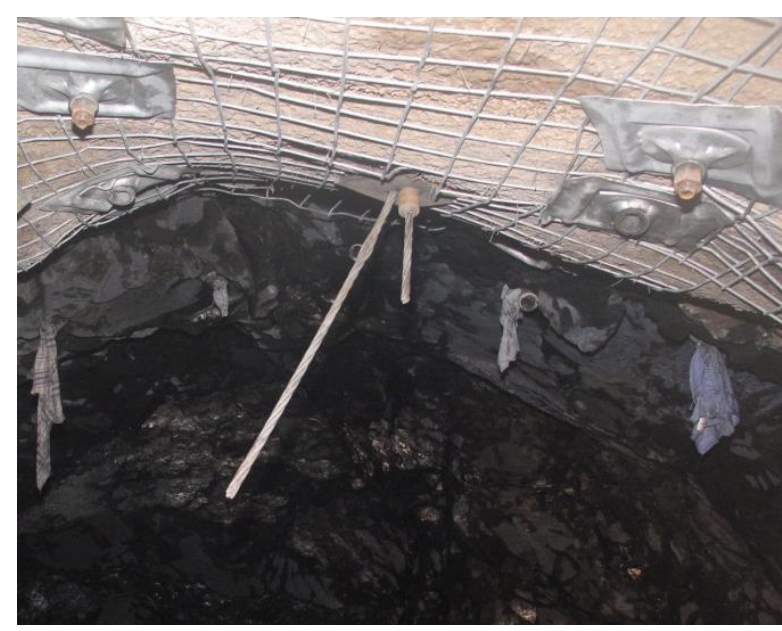

b)

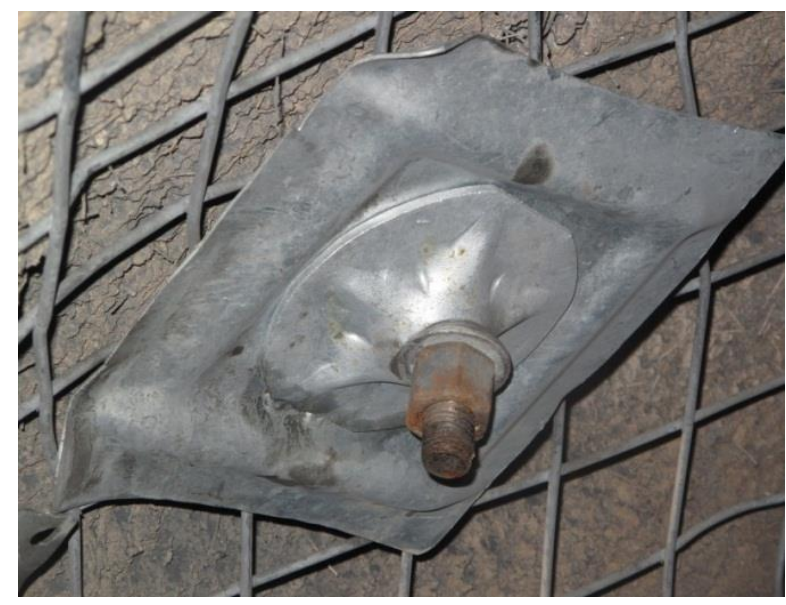

d)

Figure 4 Image a) is of the D-bolt and nut and washer configuration. Image b) shows the short tails on the D-bolts after installation. Image $c$ ) shows a tape measure up the bolt hole indicating insufficient encapsulation and Image $d$ ) shows the short tail of the $D$-bolt but also the problem of too short tail and damaged thread not allowing for pull-testing of the bolt

Recommendations for ongoing work arising out of the initial trial were made to the bolt supplier and also noted for future trials:

- A thicker thread or standard size thread was recommended for the ends of the bolts to reduce damage to the thread.

- It was found that the two part resins were not mixing well and bolts were not spinning up, therefore made recommendations to modify the end of the bolt to generate better mix.

- The trial of several different sized bits would have been useful to determine the optimal bolt hole size given the bolt diameter and the resin cartridge sizes. This was not undertaken during the D-bolt trial because it was assumed that the same bits used for the installation of Posimix bolts would be suitable due to them being of similar diameter. During the trial we noted that up to $40 \mathrm{~cm}$ of the bolt near the collar had no resin encapsulation. This suggests that the bolt holes used $(35 \mathrm{~mm})$ were too large. 
- For Cosmos purposes, the location of the first anchor set at $0.5 \mathrm{~m}$ was useless as this was well within the damage zone of the excavation. A recommendation was made to move the first anchor to $1.0 \mathrm{~m}$.

- Galvanising was necessary for Cosmos due to the hyper saline nature of the groundwater.

- In order to provide real data comparing the effectiveness of the ground support, it would have been beneficial to install extensometers in the ore drives next to the installed D-bolts and also in an ore drive comprising the standard posimix bolts.

- Dynamic Testing of the entire ground support system at the Western Australian School of Mines (WASM) would have been a good idea to put values against the effectiveness of the entire support regime and not just the singular elements.

Whilst the trial of the D-bolt had some success, the negative aspects of the bolt at the time outweighed the positives and these support elements were not implemented. Despite this, one interesting aspect of the D-bolt relates to the subsequent production in one of the oredrives selected for the trial. Following stoping in the 9600-9625 Levels, in 9625 OD1 there was comparatively low deformation and damage after production in the backs and sidewalls of the drive where the D-bolts were installed compared to the other ore drives in the level supported with posimix bolts. The other two oredrives, in the same rock type and drive orientation, showed significant rock mass damage and deformation for relatively small volumes of extraction.

\section{$4 \quad$ Omega bolt}

\subsection{Further deterioration of ground support systems}

Following the varied success of the D-bolt trial there was still significant drive closure and deformation being experienced in ultramafic rock even with existing heavy support system (fibrecrete, mesh, split sets, posimix bolts and $6 \mathrm{~m}$ de-bonded cables). The ground support regime was becoming less effective and rehabilitation was being required within weeks of initial installation.

The worst of the deformation was occurring at the deepest levels of the mine. In the case of the 9585 Level (Figure 5 - approximately $875 \mathrm{~m}$ below surface) drive closure measured at least $90 \mathrm{~mm}$ of closure occurring within 56 hours of monitoring. Over the space of one month, the closure of the drive was assessed by re-photographing the drive and processing it in AdamTech which showed that almost $1 \mathrm{~m}$ of closure had occurred in places during that time period (Figure 5).

Significant loading of the ground support elements was apparent with multiple plate and bolt failures. Numerous plates were found on the floor. On a few occasions, violent failure of posimix bolts was observed by engineering personnel. The length of bolt ejected from one hole was $1.6 \mathrm{~m}$ long and appeared to have sheared through the bolt. At least three other posimix bolts were ejected up to $0.5 \mathrm{~m}$ but not completely from the wall (Figure 6).

Further investigative work was carried out to test the resin encapsulation. A large number of bolts failed pull tests, and resin was found to have migrated into the surround rock through open fractures and joints in the surrounding rock mass. 

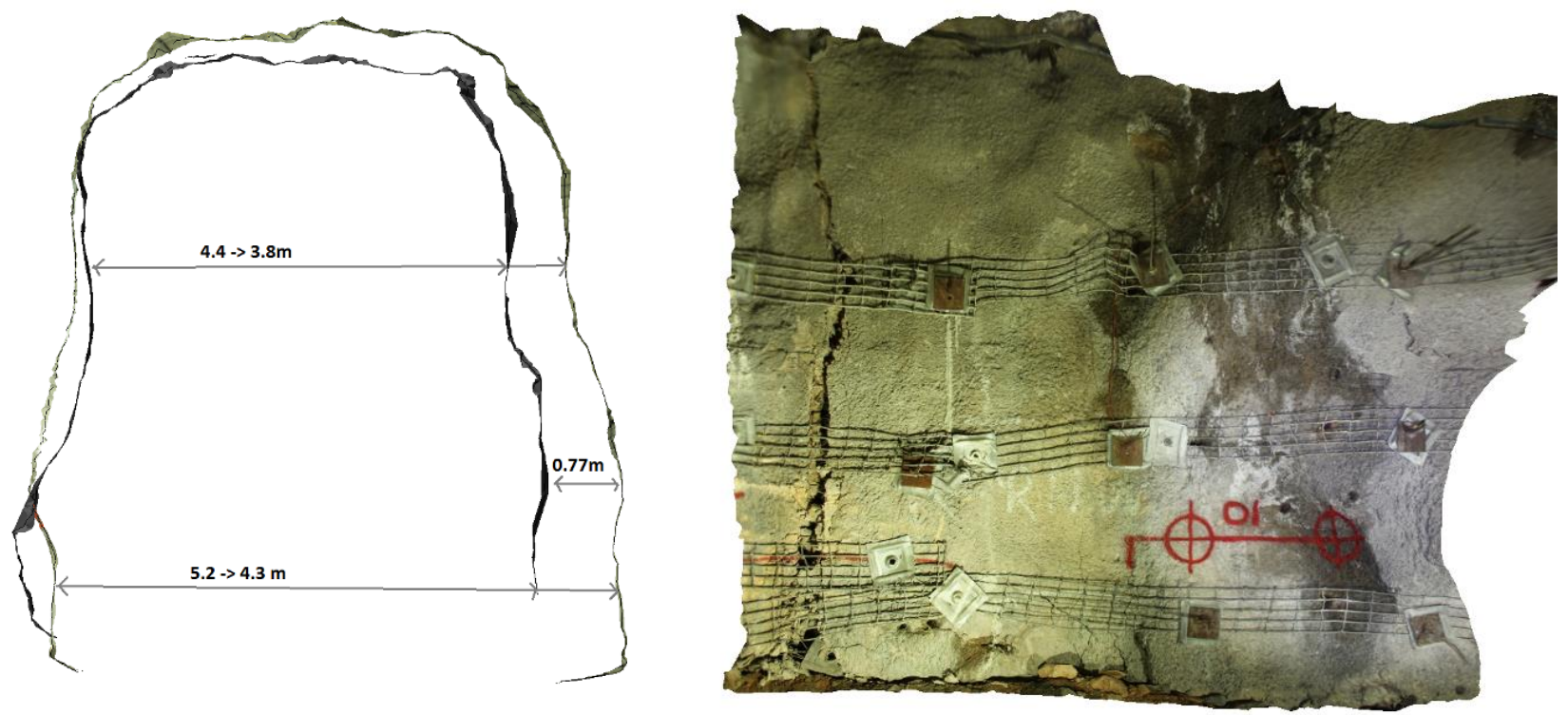

Figure 5 Cross section of the 9585 drive showing drive closure and side view of the drive using AdamTech photographs showing the cracking in the fibrecrete

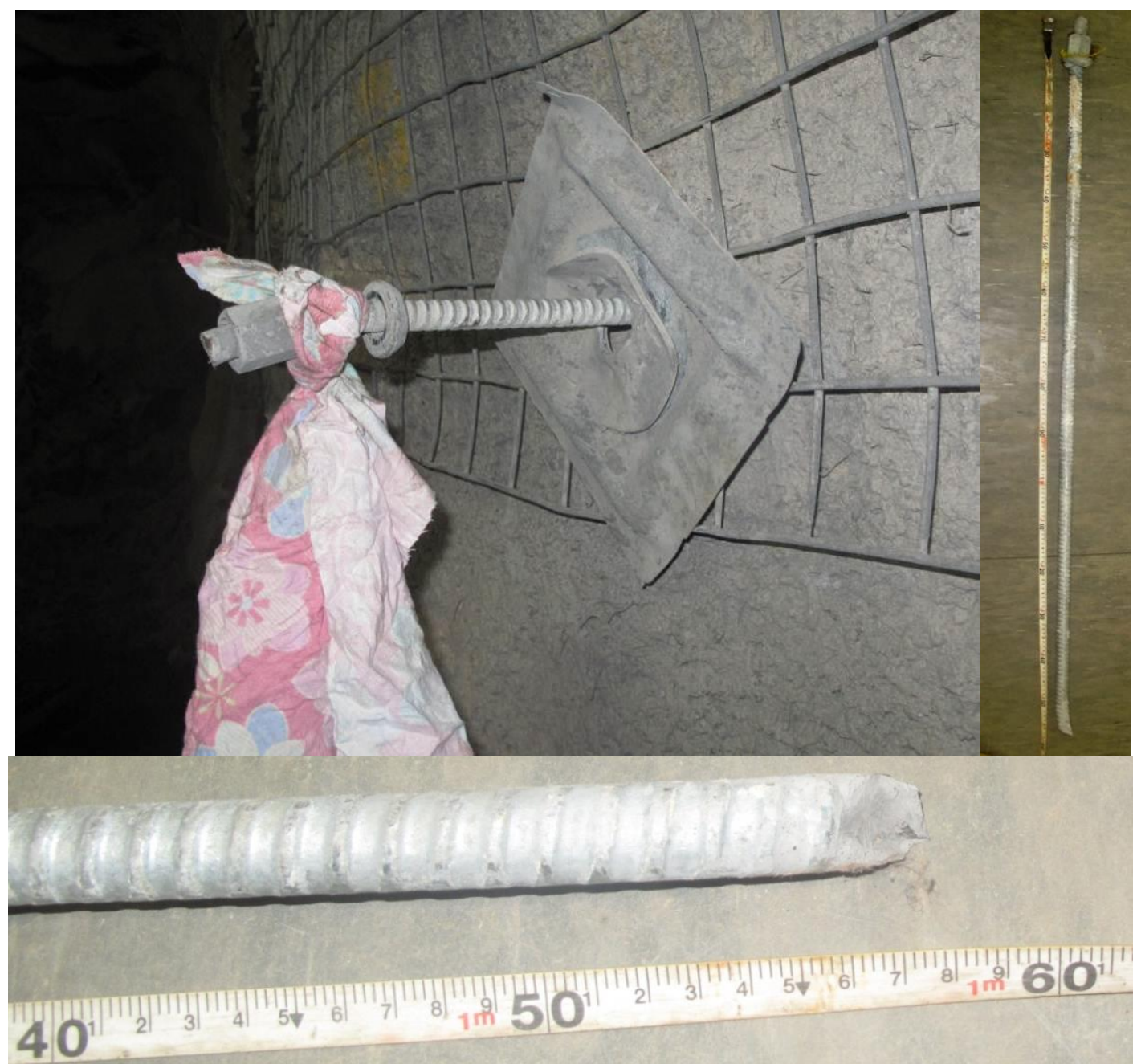

Figure 6 Examples of posimix bolt failure in the 9585 drive 
Borehole micrometre testing of drilled bolt holes in the drive was completed to see what the resulting bolt hole diameters were using the $35 \mathrm{~mm}$ posimix bolt drill bits and the $43.5 \mathrm{~mm}$ split set drill bits. This testing revealed that the $35 \mathrm{~mm}$ holes were blowing out to over $42 \mathrm{~mm}$, and the split set holes were up to $52 \mathrm{~mm}$ in the ultramafic. The hypothesis was that the hole blowout was most severe in highly serpentinised zones (high in talc also) and with the larger hole diameters insufficient resin was available to fully encapsulate the bolts.

These investigation results posed a significant issue questioning the effectiveness of the support in the ultramafic. Post-grouting of the posimix bolts could have overcome this problem, however, this process was seen as too time consuming, costly and high risk due to exposure of personnel to unsafe rock mass conditions. In addition to this, the slow development cycle did not need to be made even slower.

After discussions and site visits to other underground nickel mines in WA, it was decided to trial the Omega bolt - an expanding friction rockbolt (Supplier: DSI Mining) as an alternative bolt because they can expand over $50 \mathrm{~mm}$ in size. The Omega bolt also had a proven record of performing in ultramafic subject to squeezing conditions.

The ultimate static strength of the omega bolt is $24 \mathrm{t}$ (which is a higher capacity than the posimix bolts at $17 \mathrm{t}$ ) and an elongation potential up to $30 \%$. Because of the higher capacity immediate potential benefits were realised for using this type of bolt, i.e. bolt spacing could be increased as with ring spacing. Higher load capacity $=$ less bolts = less time $=$ faster heading turn around. If the Omega bolt trial were successful then there could be a possibility of reducing the use of de-bonded cables with connectable $3.0 \mathrm{~m}$ Omega bolts. There was also the potential to remove the split sets from the ground support regime as they were predominantly used to pin the mesh, because operators found it difficult to do this with the resin bolts alone.

\subsection{Omega rockbolt trials}

As part of the initial planning of the trial a site visit was organised to another underground nickel mine in Western Australia to view these bolts in operation, and to talk to operators and mechanical fitters. The reason for these discussions was to find out the pros and cons from a variety of viewpoints. Observation of the installation process was necessary to find out where these operators could potentially take shortcuts on installation. Discussion with site engineers on their experiences and costs were also held.

Contact was made with a highly experienced geotechnical consultant familiar with these bolts. This consultant provided very valuable and practical advice in terms of using these bolts; for example, carefully consider the use of the bitumen coated bolts, as the bitumen coating can melt in the Australian heat especially if the bolts are being stored outside.

Research into the dynamic capacity of these bolts was also undertaken, because if we were going to replace the posimix bolts, then in the felsic volcanics and meta-sediments, a bolt was needed that could provide some protection against seismicity.

The actual trial involved 900 Omega bolts (both $2.4 \mathrm{~m}$ and $3.0 \mathrm{~m}$ long) and these were installed into areas requiring rehabilitation and also new development headings. It was important to test the bolts in three different rock types; the felsic volcanics, felsic porphyry and ultramafic. The duration of the trial lasted two weeks.

The testing also involved various bit sizes in different rock types. This was to gauge which diameter drill bit would be best to use for drilling the bolt holes. As part of the investigation, the borehole micrometre was used to measure the borehole sizes and these holes were also filmed with a borehole camera to measure the depth of failure within backs and walls.

Following installation, the Omega bolts were pull tested to failure to determine capacity in Cosmos ground conditions. 
As part of the trial, the underground contractor was able to source an experienced jumbo operator and jumbo drill that was already equipped for Omega bolt installation from one of their other sites. This operator and rig was critical in the success of training the existing contractor operators at CNO. The contractor also ensured that all consumables were on site prior to the trial starting.

The Omega bolt trial proved successful in that bolts were pull tested to capacity following installation and the correct diameter bolt hole size was selected. The next phase was to implement the use of Omega bolts into the ground support standards used at the mine. Operator feedback was also positive and bolting cycle times were also significantly faster.

The implementation process involved the following steps:

1. A risk assessment as part of the change management process to identify any potential hazards that could arise from the use of these bolts and implementing the change.

2. A cost benefit analysis of the ground control system. Part of this required discussions and modifications to the existing contract between Xstrata and the contractor.

3. Update to the Ground Support Standards and Ground Control Management Plans.

4. Training of all operators and signing off on training records.

5. Training of all jumbo fitters on the use and maintenance of the Omega pump.

6. Development of site specific procedures for installation of this ground support by the contractor.

7. Information sessions and presentations to all crews explaining the change in ground support elements.

The cost of adding the bolt pump to the jumbo at the time was approximately AUD $80 \mathrm{~K}$. From the site visits it was made clear that the ongoing pump maintenance and replacement of blown ' $O$ ' rings were common problems with this equipment. It was also critical to have a suitably trained maintenance fitter to look after the pumps.

\section{$5 \quad$ Resin encapsulated cable bolts}

The use of in-cycle de-bonded cables used in all ultramafic development at Cosmos was time consuming and cost prohibitive, causing delays in production and the development cycle. One of Xstrata Nickels Canadian mines had recently trialled a pumpable resin which was very successful there. The Canadian Engineers concluded that there was excellent bonding between the cable and resin (from overcoring) and also that there was some resin migration into rock mass based on observations of the surrounding rock following a rockburst. Using the quick set resin they had noted a rapid increase in development turnaround times.

The following points summarise the benefits of the resin product:

- Faster set strength and time of $70 \mathrm{MPa}$ UCS after one hour.

- Faster installation.

- Reduced cycle time due to rapid setting speed of the resin enabling headings to be fired in the same shift as installation.

- Better encapsulation.

- Removed human error associated with mixing grout because it is an engineered product.

Based on these reviews it was recommended to CNO to try this product. However, when CNO contacted the supplier in Australia it became apparent that it was not the same as their Canadian counter-parts. The products manufactured in Australia were slightly different. 
Trial \#1 was set up with little success due to limited experience in WA metaliferous operations. Furthermore, setting times were rapid and blocked the injection nozzle nearly every time. As this was a two component resin, component $B$ also coagulated in pump lines over night requiring complete rebuilding of the pump. What also became apparent was that the products were temperature sensitive and in the Canadian mine they had only been tested at $22^{\circ} \mathrm{C}$. CNO underground temperatures were considerably warmer than this which enabled the reaction to proceed faster. Another product was also tested and was marginally more successful but only had a UCS of $18 \mathrm{MPa}$. However, this product also set too quickly resulting in only partial encapsulation of the cable bolts.

Pressures in the delivery tubes were high causing blow outs in feeder tubes during the trial. The equipment used for pumping and transporting these products was cumbersome.

Using the learnings associated with the first trial, a second trial was commissioned. An appropriate pump was sent to Australia after communication between the supplier in Canada and Australia. Two operators who were familiar with the use and also the development of the product were also sent to site for a trial. This time, the trial comprised the drilling of ten (10) cable bolt holes drilled to $6 \mathrm{~m}$ and $64 \mathrm{~mm}$ in diameter. Different types of feed pipes were also trialled: $6 \times$ Chlorinated Poly Vinyl Chloride (CPVC), $2 \times$ glass fibre reinforced plastic tube (GRP), and $2 \times$ standard grout tube. Trial \#2 only involved twin strand, bulbed cable bolts which were typically used in intersections.

During Trial \#2 the set time of the resin was still too fast, around 40 seconds. Full encapsulation was not achieved as product set too quickly in the hole (approximately 0.5 to $2.0 \mathrm{~m}$ from collar). It was concluded that hole diameter was a contributing factor to the problem and the holes were probably slightly too big. The cable-bolts were pull tested approximately one hour following installation and none failed despite the lack of encapsulation.

However, each of these trials was of a relatively high cost. The cost for the product only in Trial \#2 was AUD 21,000 which worked out to be the equivalent of AUD 9.50/kg. Considering that each hole used between 20 to $30 \mathrm{~kg}$ per hole this meant that the resin cost per hole was on the order of AUD 190 to AUD 285 each.

Based on the success of the product in Canada, and improvements in the second trial, Xstrata Nickel Australasia (XNA) was keen to continue the development of this technology. A third and final trial was planned. In Trial \# 3, XNA asked the supplier to slow the catalytic reaction down to two minutes, and make a product more suited to a range of temperatures present in Australian underground mines. Also, the initial trials were expensive but XNA was hoping for more competitive costs in the future for higher quantities ordered.

In the final trial a total of 48 cable bolts were tested in the two predominant rock types (felsic volcanics and ultramafic) and in two different areas of the mine. The trial also used a smaller $51 \mathrm{~mm}$ cable bolt hole diameter instead of $64 \mathrm{~mm}$, which meant that less volume was required to fill the holes. All cable bolts were fully encapsulated with the resin coming out of bottom of the holes (Figure 7).

A variety of cable bolt types were also investigated including; de-bonded cables, twin strand bulbed, single strand bulbed and single strand plain, to see if there was any difference in the strengths and pull out loads obtained from the different configurations. All of the installed cable bolts were pulled to $25 \mathrm{t}$ or failure within 30 minutes to one hour of installation. Elongation was noted on bulbed bolts in the order of $10-15 \mathrm{~cm}$.

The third trial was considered a success. As a result implementation procedures were started. The first item on the agenda involved liaising with the underground mining contractor to come up with an efficient way of storing the product and delivering product (i.e. construction of a new IT basket). The trial set up was cumbersome and not efficient for mining as only a small amount of product could be used at a time and a second pallet of $25 \mathrm{I}$ drums of the two different components had to be moved around (Figure 8). 


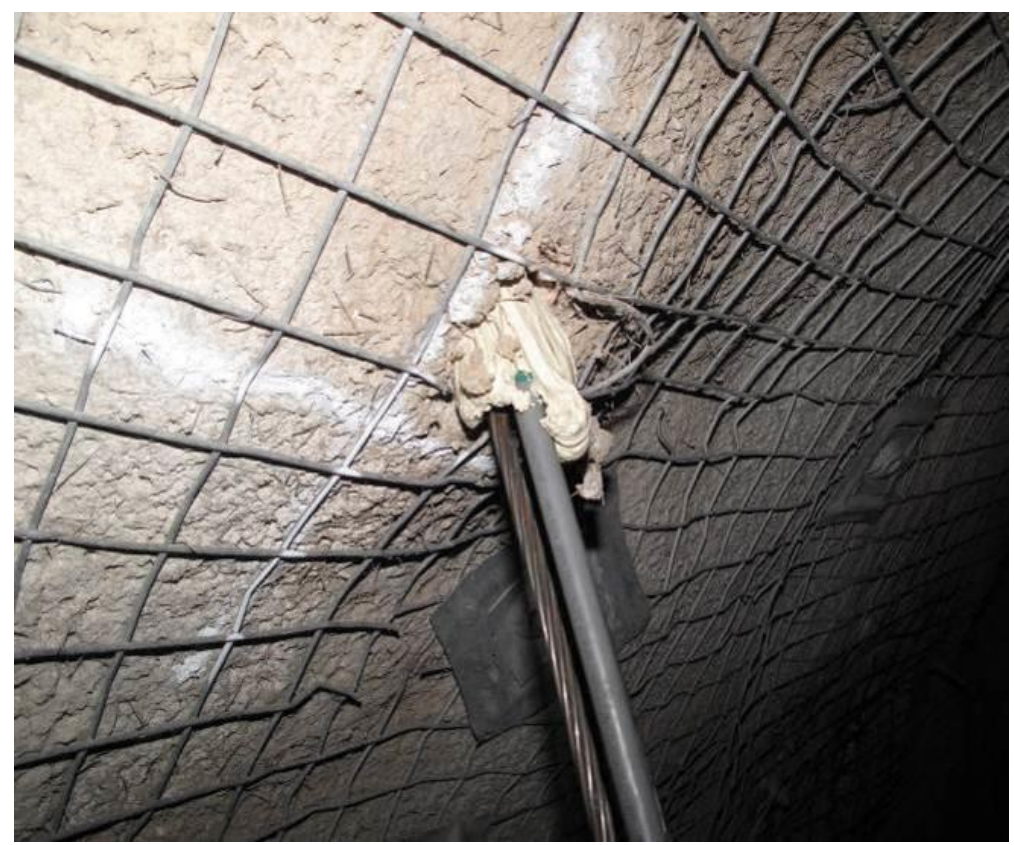

Figure 7 Cable bolt installed with CPVC feeder tube showing the resin coming out the bottom of the hole

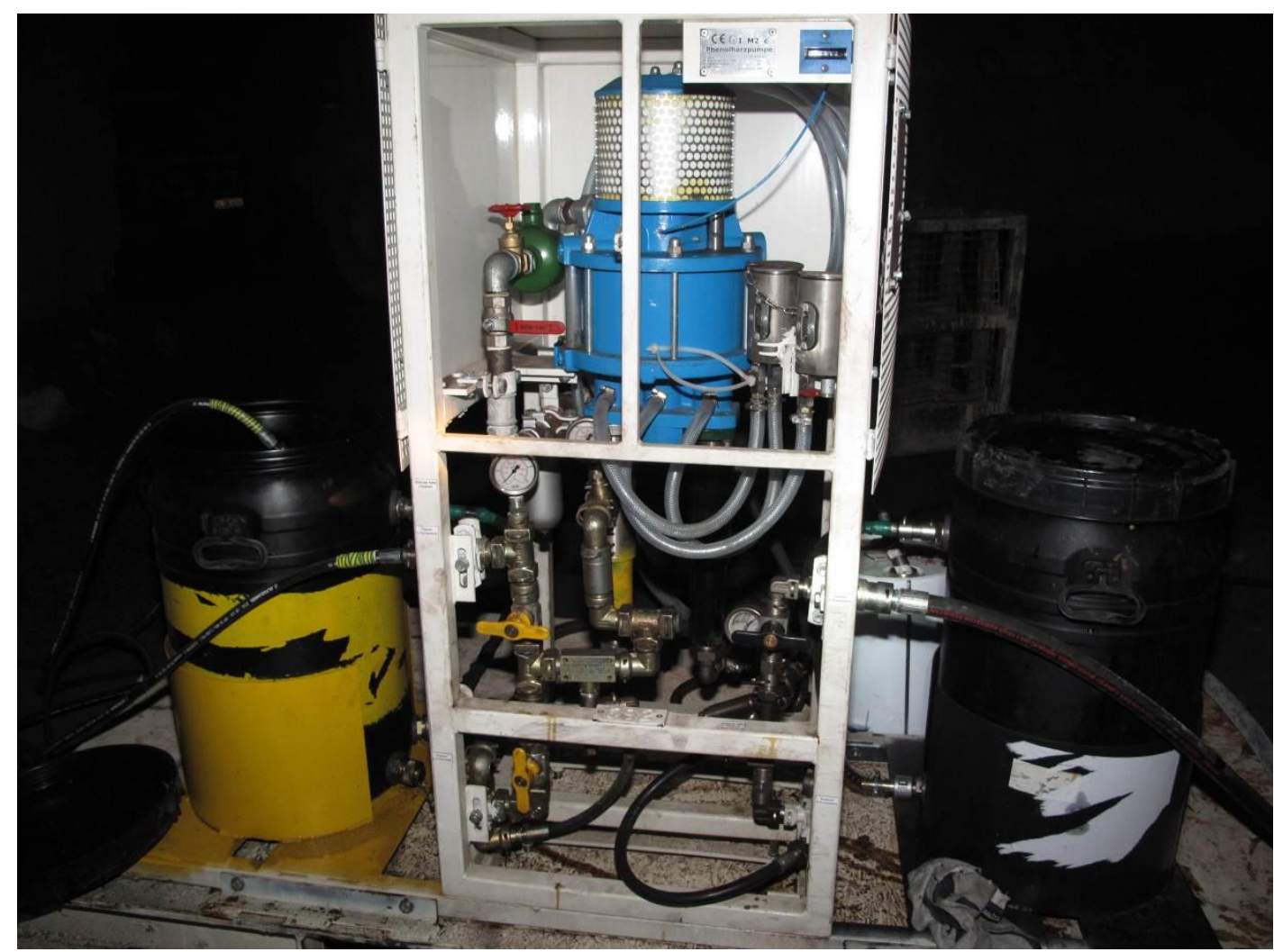

Figure 8 Set up of high pressure pump for the resin product, note the two small storage containers either side of the pump for each of the components

\section{Conclusions}

As a result of a number of ground support trials undertaken at $\mathrm{CNO}$ and drawing on the experience of the authors, the following points and questions are intended to form a basic framework for the trial and implementation of new ground support elements in an underground mine: 
1. What problem would you like to fix and why? (i.e. what is driving the change - is it the ground conditions or for a reduction in ground support costs?).

2. Do you understand the problem, i.e. are the bolt holes big/small enough, is the ground more fractured, are the bolt holes 'blowing out' after drilling?

3. Undertake field investigations and QAQC tests to get a good handle on the ground conditions and the causes of the problems.

4. Research different ground support options. Ask questions at the Ground Control Group meetings. Talk to your peers, talk to other sites that might use or have trialled particular ground support or reinforcement elements and try to go visit a site that uses them. Do not forget to talk to everyone involved in the ground control process, especially the operators, engineers, managers and fitters. Get everyone's opinion and find out all the pros and cons and especially where operators might take short cuts.

5. Investigate the cost benefits and disadvantages. If it saves money then people are more likely to be receptive to change. Maybe your idea will cost more, but the time you could save in development schedules would create savings in other areas. Sometimes you need to look at the bigger picture.

6. Decide on the area where you will undertake the ground support trial. Make sure that a representative sample of ground conditions and rock types are being tested. Also consider that maybe testing a new technology or bolt in a high traffic area (i.e. crib room/magazine/decline) may not be a good idea if you don't know that it is going to work. You want to do the testing somewhere that you can monitor changes easily and rehabilitate them if required. Always do a risk assessment before starting.

7. Decide on how you are going to test the success of the ground support.

8. Write up the results of the trial. Keep everyone informed at the various stages of the process.

9. Implementation. Find out what the change management process is on site. Ensure that a risk assessment has been undertaken and that all stakeholders have been informed: management, operators, and engineers. Presentations and posters can be effective mediums for knowledge and information transfer.

10. Consider the correct training of the operators - who is going to do it? How long will it take them to get up to speed? Ensure that the development schedule is adjusted to account for any new ground support system. Spend lots of time observing and getting feedback from the operators.

11. Ongoing monitoring and QAQC - feedback needs to be given to management and operators.

12. Track cost changes and/or production trends - are there any relationships that you can identify? Always communicate the positives back to the operators and management team.

The above points are not an exhaustive list, but reflect the type of questions that need to be asked by site based geotechnical engineers when undertaking a ground support trial. New technologies or new ways of applying different ground control elements are not always successful, nor are they necessarily the cheapest option. However, it is important to document all aspects of the trial, make worthwhile observations and learn from mistakes. Realise that it is important to see the bigger picture and that short term losses in cost, may be negated by long term gains.

\section{Acknowledgement}

The authors would like to thank the management team at Xstrata Nickel Australasia for their willingness to try new things and for use of observations and data used in this paper. 